\title{
Suitability of different biomaterials for the application in tire
}

\author{
Sambhu Bhadra ${ }^{1}$ (i) $\cdot$ Nitin Mohan ${ }^{1} \cdot$ Sujith Nair $^{1}$
}

Received: 13 August 2019 / Accepted: 1 November 2019 / Published online: 5 November 2019

(c) Springer Nature Switzerland AG 2019

\begin{abstract}
Biomaterials are obtained from renewable sources, low cost, abundant supply, environmentally friendly, fossil free and biodegradable. Therefore, the main objective of the present research is to use different biomaterials, such as carbohydrates (starches, celluloses), proteins and lignin in tire compounds without compromising tire properties and gaining possible advantages in terms of properties, cost, weight and environment. We have incorporated (10 phr, top up) different type of starches, such as maize, wheat, rice, cassava, and cellulosic materials, such as microcrystalline cellulose, sodium carboxymethyl cellulose, natural proteins, such as soya bean flour, and lignin in a silica filled tire tread compound and measured the properties to investigate if any of those materials can be used in tire. Among all these biomaterials, cassava, lignin and soya accelerate rate of vulcanization. Therefore, these materials can be used as bio-accelerator. Soya proteins imparts approximately $11 \%$ improvement in tensile strength and approximately $10 \%$ improvement in elongation at break. After the addition of biomaterials there is increase in marginal rolling resistance, increase in Payne effect and significant deterioration in wear property. Soya protein accelerate rate of vulcanization, improves mechanical properties, shows minimum deterioration in properties after ageing. Therefore, soya protein is the most suitable biomaterials among the materials studied for application in tire compound.
\end{abstract}

Keywords Starch · Cellulose $\cdot$ Lignin · Soya $\cdot$ Rubber $\cdot$ Tire

\section{Introduction}

Major parts of natural rubber (NR), styrene butadiene rubber (SBR), butadiene rubber (BR) are used in tire manufacturing. Most of the synthetic polymers and few other ingredients of the tire compound are obtained from fossil based raw materials. Enormous effort is going on to produce products from fossil free biomaterials to contribute towards the conservation of global environment. It can be done in most efficient way by using biomaterials, such as carbohydrates (starches, celluloses), proteins and lignin in tire compounds. Biomaterials are obtained from renewable sources, low cost, abundant supply, environmentally friendly and biodegradable. Several studies have been carried out on the incorporation of biomaterials in rubber compounds.
Nakason et al. synthesized natural rubber and poly(methyl methacrylate) (NR-g-PMMA), compounded with cassava starch and studied the curing characteristics of the compound. They observed that the tensile strength, elongation at break and tear strength were decreased with the increasing levels of the cassava starch [1]. Nakason et al. [2] in their separate study prepared maleated natural rubber (MNR), blended with cassava starch and investigated rheological properties and curing characteristics. Liu et al. modified starch paste (MST) with polybutylacrylate (PBA) and used it as a reinforcing filler for natural rubber (NR). They observed that unmodified starch filler acts as a non-reinforcing filler and decreases of tensile strength, tear strength and elongation at break. Whereas, MST acts as reinforcing filler and increases tensile strength, elongation at break and

Sambhu Bhadra, sambhu.bhadra@ceat.com; bhadra_sambhu@yahoo.com | 1R\&D, Ceat Ltd., Halol, Gujarat 389350, India. 
tear strength besides modulus and hardness because of better and strong interfacial interaction in NR/MST composites [3]. Tang et al. modified starch with resorcinol-formaldehyde and $N$ - $\beta$ (aminoethyl)- $\gamma$-aminopropyl trimethoxy silane (KH792) and then compounded in styrene-butadiene-rubber (SBR). They observed the improvement in mechanical properties, which was comparable with that of carbon black reinforced composite $[4,5]$. Ping et al. prepared rubber/starch composites by directly mixing and co-coagulating rubber latex and starch paste. The composites exhibited higher hardness, stress at $100 \%$, tensile strength, and tear strength compared to the rubber/starch composites prepared by direct blending [6]. Li et al. synthesized three types of modified starches (MST); starch-g-poly(butyl acrylate) (ST-g-PBA), starch-g-poly (methyl methacrylate) (ST-gPMMA) and starch-g-polystyrene (ST-g-PS) latexes by emulsion polymerization and then compounded with styrene-butadiene rubber (SBR) latex in order to prepare MST/SBR compounds and then investigated characteristics, morphology, swelling, mechanical and dynamic mechanical properties. There was improvement in dispersion and mechanical properties because of the modification of starch [7]. Li et al. [8] studied the effect of coupling agents in the poly (methyl methacrylate)-modified starch/styrene-butadiene rubber interfaces and reported the improvement in reinforcement because of the presence of coupling agent. Angeller et al. $[9,10]$ prepared nano composite from NR latex and waxy maize starch nanocrystals and found significant improvement in barrier properties, mechanical properties and relaxed modulus. Corvasce et al. [11-13] developed starch/ plasticizer filled rubber compound for application in tire tread compound which significantly reduces rolling loss. Paul et al. prepared rubber composites containing a combination of starch, modified starch and/or starch/ plasticizer composite together with selected methylene donor and/or methylene acceptor compounds for low rolling resistance tire application [14, 15]. Haghighat et al. added a-cellulose powder to styrene-butadiene rubber (SBR) rubber and physico-mechanical properties were measured. They observed the increase in Young's modulus, hardness, and compression set and decrease in elongation and resilience with increasing a-cellulose loading in the composites, whereas tensile strength, tear strength, and abrasion resistance initially increased at low a-cellulose concentration ( $5 \mathrm{phr}$ ), after which these properties decreased with increasing a-cellulose content [16]. Zhang et al. synthesized surface-acetylated cellulose powder (SACP) and incorporated in NR based compound. They observed the improvement in mechanical properties of the composite because of the acetylation of cellulose [17]. Cao et al. prepared carboxylated styrene-butadiene rubber (XSBR)/cellulose nanocrystals (CNs) latex composites and investigated morphology, dynamic viscoelastic behavior, dynamic mechanical property, thermal and mechanical properties. The composites exhibited a significant enhancement in tensile strength and tear strength with 0 to $15 \mathrm{phr}$ of CNs loading [18]. Abraham et al. separated cellulose nanofibres (CNF) from raw banana fibres by steam explosion process and used as reinforcing fibre in NR based compound. They observed significant improvement of Young's modulus and tensile strength because of the addition of CNF to the rubber matrix [19]. Lopattananon et al. incorporated short cellulose fibers in silica filled NR compound. There was improvement tensile modulus, but deterioration of tensile strength and elongation at break with increasing cellulose fibre content [20]. Chen et al. prepared nanocrystalline cellulose (NCC) reinforced natural rubber/butadiene rubber/styrenebutadiene rubber (NR/BR/SBR) composites. They used resorcinol and hexamethylene tetramine $(\mathrm{RH})$ to modify the interface between NCC and rubber matrix. NCC exhibited comparable reinforcing effect with carbon black [21]. Bhal et al. prepared hybrid fillers by precipitating lignin from solutions onto carbon black particles. The hybrid fillers formed much less network than virgin $\mathrm{CB}$, resulting reduction in viscoelastic dissipation [22]. Lora et al. [23] observed that lignin acts as a tackifier as well as an antioxidant in rubber compounds. Jiang et al. [24] prepared nano-lignin and its composites with natural rubber, which exhibited improved dispersion and mechanical properties. Kosikova et al. incorporated 10-30 phr (parts per hundred parts of rubber) lignin in NR. Lignin reduced the thermooxidative degradation of NR vulcanizates to in air [25]. They extended this study using styrene butadiene rubber (SBR) as polymer matrix [26]. Kumaran et al. incorporated lignosulfonate in NR. They observed that modulus, tensile strength, resilience, heat build-up, and compression set properties were deteriorated after the incorporation of lignosulfonate [27]. Barana et al. extracted lignin from different sources and by different processes was incorporated in NR. They observed that difference in the chemical and morphological characteristics of lignin influence its antioxidant and reinforcement capability [28]. Davidson et al. recovered SBR from its aqueous polymerization emulsion by coagulation with acid and a lignin compound. By this process, the porosity of rubber crumb was increased 
[29]. Yu et al. investigated the influence of lignin/silica hybrid filler in natural rubber vulcanizate and found that the incorporation of lignin into the rubber weaken the Payne effect and improve the processability, antiaging resistance and anti-flex cracking of composites [30]. Jong incorporated defatted soy flour (DSF) in SBR latex to form elastomer composites. The inclusion of DSF increased the tensile stress in the small strain region but reduced the elongation at break [31]. Jong [32] in separate studies incorporated soy spent flakes (SSF) and soy protein concentrate (SPC) [33] in SBR latex and found similar stress versus strain properties. J. Long also incorporated co-filler containing a mixture of soy spent flakes (SSF) and carbon black (CB) in SBR latex. There was 100 times increase in the shear elastic modulus compared with unfilled SB rubber by the addition of $30 \%$ co-filler [34]. Mohanty et al. [35] made elastic rubber band from lignin blended in NR. Wu et al. incorporated soy meal in natural rubber compound. They observed that even after addition of $50 \mathrm{wt} \%$ of soy meal the compound was still elastic and water resistant [36]. Several studies on utilization of biomaterials in tire compound have also been carried out in tire industries. Goodyear manufactured tire using starch/plasticizer composite as filler [ 1 , $15,37,38]$. Michelin also developed similar type starch/ plasticizer composites for application in tire [39]. Cellulose and lignin materials have also been used in tire compound [40-45].

From above literature survey it appears that biomaterials, such as carbohydrates (starches, celluloses), proteins and lignin imparted better properties in rubber compound when those are chemically modified and/or added in conjugation with some other chemicals, such as plasticizer, compatibilizer etc. However, modification come with cost and sometime industrially not viable. There is no literature on comparative study of these virgin biomaterials (without any modification or compatibilizing agent) in tire compound. A comprehensive comparative report on utilization of low-cost and abundantly available biomaterials, such as carbohydrates (starches, celluloses), proteins and lignin in its virgin state (without any modification or compatibilizing agent) in tire compound will enable the tire industry to select suitable biomaterial for specific need. Therefore, the objective of the present research is to incorporate virgin biomaterials, such as carbohydrates (starches, celluloses), proteins and lignin in tire compound and detailed characterization.

\section{Experimental}

\subsection{Materials}

Solution styrene butadiene rubber (s-SBR) and butadiene rubber (Nd-BR) were procured from Reliance Industries, India, Carbon black (N330) was bought from Philips Carbon Black Ltd., India, active granular precipitated silica (ULTRASIL) and bifunctional, sulphur-containing organosilane coupling agent (Si69) were supplied by Evonik, zinc oxide ( $\mathrm{ZnO}$ ) was procured from Rubamin, India, stearic acid was bought from Godrej, India, process oil (treated distillate aromatic extracted; TDAE) was obtained from Rajpetro, India, microcrystalline wax was procured from Repsol, India, N(1,3-dimethyl-butyl)-N'-phenyl-Pphenylenediamine (6PPD), Cyclohexylthiophthalimide (CTP), N-cyclohexyl-2-benzothiazole sulfenamide (CBS) were procured from Nocil Ltd., India, sulphur was obtained from Estman, India, starches, microcrystalline cellulose (MCC), sodium carboxymethyl cellulose (CMC), lignin, and soy bean flour were procured from Ganesh Scientific, India, Diphenyl guanidine (DPG) was obtained from Yasho, India. Images of plants and their powders of different biomaterials are shown in Fig. 1 and Properties are provided in Table 1.

\subsection{Mixing}

A standard silica-based passenger car tire tread formulation was taken as control and different biomaterials were topped up into it as shown in Table 2. The compounds were mixed in Kobelco intermix, Mixtron BB-L3200 IM, Kobe, Japan. $62 \%$ fill factor (FF) was maintained. Mixing was performed in three steps; (i) preparation of master, (ii) repass, (iii) final mixing with curatives.

Step 1: Preparation of master At first, all rubbers were incorporated and mixed for $45 \mathrm{~s}$ at a speed of 60 RPM. Then half of all ingredients (except curative system) were incorporated and mixed again for $60 \mathrm{~s}$ at a speed of 60 RPM. After that, rest half of the ingredients were incorporated and mixed again for $45 \mathrm{~s}$ at a speed of 60 RPM. Finally, the mixing was continued for $340 \mathrm{~s}$. At this stage the RPM was varied to maintain the temperature at $150^{\circ} \mathrm{C}$.

Step 2: Repass The master was kept overnight for relaxation. Next day, it was re-mixed for $210 \mathrm{~s}$ at 70 RPM.

Step 3: Final mixing with curatives All the master and curatives were incorporated and mixed for $200 \mathrm{~s}$. At this stage the temperature was maintained below $100{ }^{\circ} \mathrm{C}$ through RPM control. 


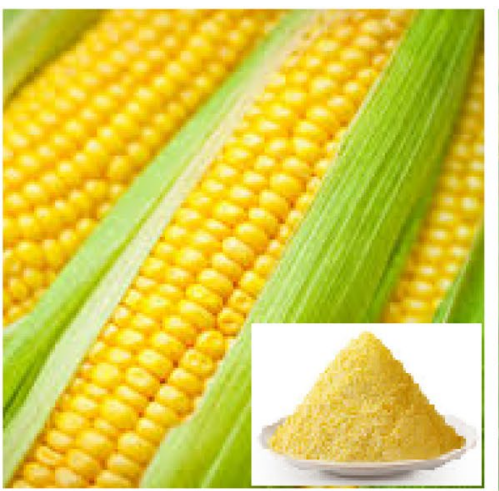

Maize/Corn

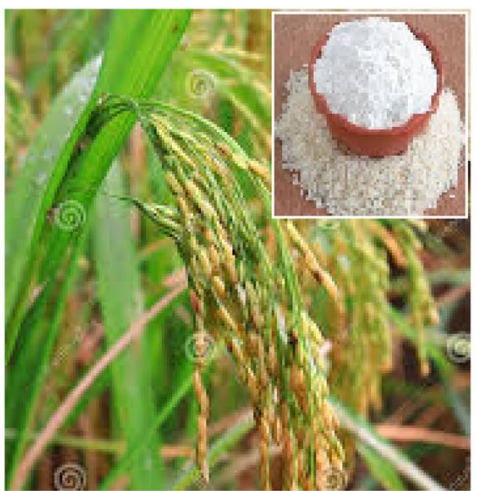

Rice

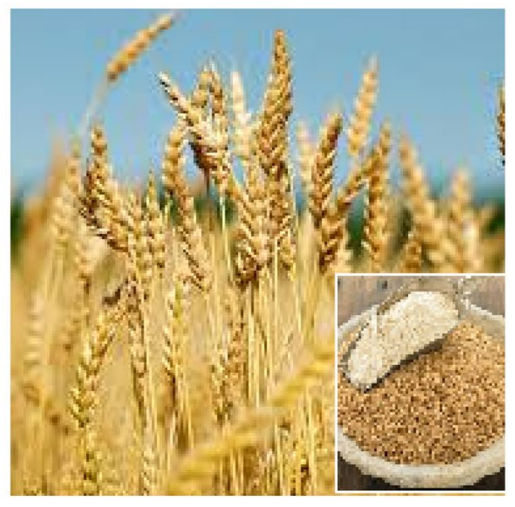

Wheat

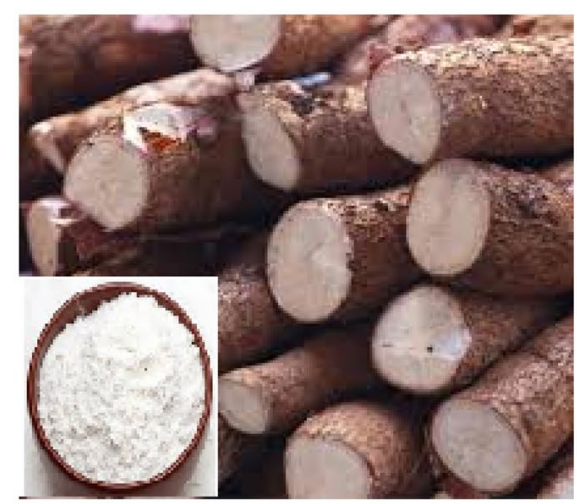

Cassava/Tapioca

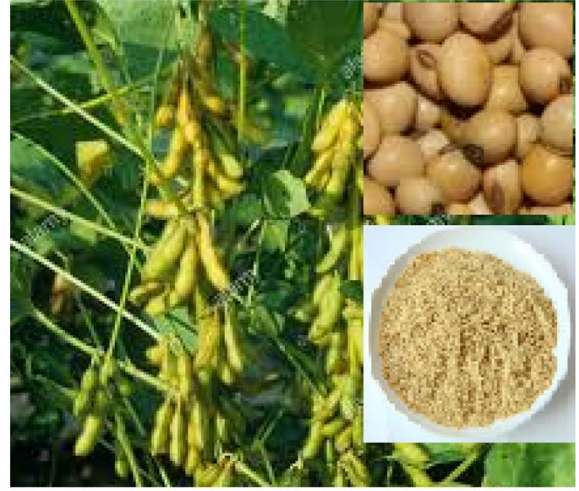

Soya bean

Fig. 1 Images of plants and their powders of different biomaterials

Table 1 Properties of bio materials (all in powder form)

\begin{tabular}{lllllllll}
\hline & Maize & Rice & Wheat & Cassava & MCC $^{\text {a }}$ & CMC $^{\mathrm{b}}$ & Lignin & Soya \\
\hline Moisture (\%) & 11.0 & 13.1 & 11.5 & 10.0 & 6.4 & 8.8 & 10.1 & 7.7 \\
$\mathrm{pH}$ & 5.6 & 6.3 & 6.2 & 6.2 & 6.0 & 6.8 & 6.7 & 6.4 \\
Particle size & & & & & & & & \\
D10 (micron) & 9.7 & 7.9 & 10.6 & 11.9 & 8.9 & 10.1 & 11.1 & 11.9 \\
D50 (micron) & 14.7 & 14.6 & 29.4 & 25.9 & 19.6 & 27.2 & 24.2 & 22.8 \\
D90 (micron) & 21.3 & 126.4 & 160.7 & 193.2 & 146.3 & 151.1 & 164.5 & 188.9 \\
Melting point $\left({ }^{\circ} \mathrm{C}\right)$ & 298 & 302 & 297 & 280 & 276 & 274 & 268 & 302 \\
\hline
\end{tabular}

${ }^{a}$ MCC Microcrystalline cellulose

${ }^{\mathrm{b}} \mathrm{CMC}$ Sodium carbomethoxymethyl cellulose

\subsection{Testing}

After mixing, rheometric test was performed at $160^{\circ} \mathrm{C}$ for 45 min using Moving Die Rheometer, MDR 3000, MonTech. The test was performed at a constant oscillation frequency of $1.67 \mathrm{~Hz}$ and constant oscillating strain of $0.5^{\circ}$ in accordance with ASTM D5289. After rheometric analysis, green rubber compound was converted into cured rubber sheet by curing/moulding in a tensile mould at $160^{\circ} \mathrm{C}$ for $25 \mathrm{~min}$, tensile specimens of dumbbell shape were cut using die punch from the cured sheet, and then stress versus strain test was performed using Universal testing machine (UTM), Strograph AE, supplied by Toyoseiki, Japan. The test was performed according to ASTM D412, $C$ type dumbbell specimen was used, distance between grips was $60 \mathrm{~mm}$ and stretching speed $500 \mathrm{~mm} \mathrm{~min}^{-1}$. For each sample 5 specimen were tested and mean of 5 results were reported. 
Table 2 Formulation of silica-based passenger car tire tread compound as control and topping up of different biomaterials

\begin{tabular}{llrrrrrrrr}
\hline Material & Unit & Control & Maize & Rice & Cassava & MCC & CMC & Lignin & Soya \\
\hline SBR & phr & 70.0 & 70.0 & 70.0 & 70.0 & 70.0 & 70.0 & 70.0 & 70.0 \\
BR & phr & 30.0 & 30.0 & 30.0 & 30.0 & 30.0 & 30.0 & 30.0 & 30.0 \\
Silica & phr & 60.0 & 60.0 & 60.0 & 60.0 & 60.0 & 60.0 & 60.0 & 60.0 \\
Silane & phr & 9.6 & 9.6 & 9.6 & 9.6 & 9.6 & 9.6 & 9.6 & 9.6 \\
Carbon black & phr & 10.0 & 10.0 & 10.0 & 10.0 & 10.0 & 10.0 & 10.0 & 10.0 \\
Biomaterials & phr & 0.0 & 10.0 & 10.0 & 10.0 & 10.0 & 10.0 & 10.0 & 10.0 \\
ZnO & phr & 3.0 & 3.0 & 3.0 & 3.0 & 3.0 & 3.0 & 3.0 & 3.0 \\
Stearic acid & phr & 2.0 & 2.0 & 2.0 & 2.0 & 2.0 & 2.0 & 2.0 & 2.0 \\
Process oil & phr & 20.0 & 20.0 & 20.0 & 20.0 & 20.0 & 20.0 & 20.0 & 20.0 \\
Wax & phr & 2.0 & 2.0 & 2.0 & 2.0 & 2.0 & 2.0 & 2.0 & 2.0 \\
6 PPD & phr & 2.5 & 2.5 & 2.5 & 2.5 & 2.5 & 2.5 & 2.5 & 2.5 \\
Sulphur & phr & 1.8 & 1.8 & 1.8 & 1.8 & 1.8 & 1.8 & 1.8 & 1.8 \\
CBS & phr & 1.4 & 1.4 & 1.4 & 1.4 & 1.4 & 1.4 & 1.4 & 1.4 \\
DPG & phr & 1.8 & 1.8 & 1.8 & 1.8 & 1.8 & 1.8 & 1.8 & 1.8 \\
CTP & phr & 0.2 & 0.2 & 0.2 & 0.2 & 0.2 & 0.2 & 0.2 & 0.2 \\
\hline
\end{tabular}

${ }^{a}$ phr parts per hundred parts of rubber
Dynamic mechanical analysis (DMA) was performed as per ASTM D5992-2018 using DMA + 450, MetroVib. Specimen with dimension $20 \times 6 \times 2 \mathrm{~mm}$ were cut from cured sheet, fixed in tension fixture and then isothermal testing was performed at $60^{\circ} \mathrm{C}$ in tension mode at $10 \mathrm{~Hz}$ frequency at $0.0 \pm 0.25 \%$ strain, where static strain is $0.0 \%$ and dynamic strain is $0.25 \%$. The $\tan \delta$ value obtained under these test conditions shows good correlation with rolling loss of the passenger car tire.

Payne effect was measured using Dynamic Rubber Process Analyzer (D-RPA 3000) from Mon Tech. RPA was performed at a constant temperature of $100^{\circ} \mathrm{C}$, frequency of $1 \mathrm{~Hz}$ and a strain range of $0.5-450 \%$.

The ABRASION resistance index of the rubber components was evaluated in a DIN Abrader from Karl Frank, Germany. The experiment was carried out as per ASTM D 5963.

The thermal stability of the compounds was performed using thermogravimetric analyser (TGA), TGA-4000 from Perkin Elmer, USA. Initially material was heated from 50 to $560^{\circ} \mathrm{C}$ in nitrogen atmosphere, followed by from 560 to $810^{\circ} \mathrm{C}$ in oxygen atmosphere at a heating rate of $20^{\circ} \mathrm{C} /$ min. In nitrogen atmosphere organic materials (all materials except carbon black, $\mathrm{ZnO}$, and silica) decompose within $560{ }^{\circ} \mathrm{C}$, remaining carbon black decomposes in oxygen atmosphere from 560 to $800{ }^{\circ} \mathrm{C}$ and silica \& zinc oxide remains as undecomposed ash.

\section{Results and discussion}

\subsection{Optimization of dosage of biomaterials in tire compound}

The required dosage of biomaterial was optimized by varying concentration of maize starch in standard formulation (Table 2). With $10 \mathrm{phr}$ of addition of starch, both tensile strength and elongation at break (Fig. 2) were increased, with further increasing the dosage of starch both the properties were deteriorated. Therefore, for further study with all bio materials, dosage was fixed to $10 \mathrm{phr}$.

Therefore, for further study different types of biomaterials, such as maize starch, wheat starch, rice starch, cassava starch, MCC, CMC, lignin and soya flour were added (10 phr top up) in silica-based passenger car tire (PCR) tread compound and different properties were investigated thoroughly.

\subsection{Curing characteristics}

Curing characteristics of all rubber compounds containing different biomaterials (10 phr, top up) were performed using Moving Die Rheometer (MDR). Figure 3 shows the rheo-graph (time vs. torque at $160^{\circ} \mathrm{C}$ ) for compounds containing different type of biomaterials. Increase in torque indicates formation of crosslinks. During first $5 \mathrm{~min}$ 

of maize starch on the tensile strength and elongation at break of the rubber compound
Fig. 2 Effect of concentration

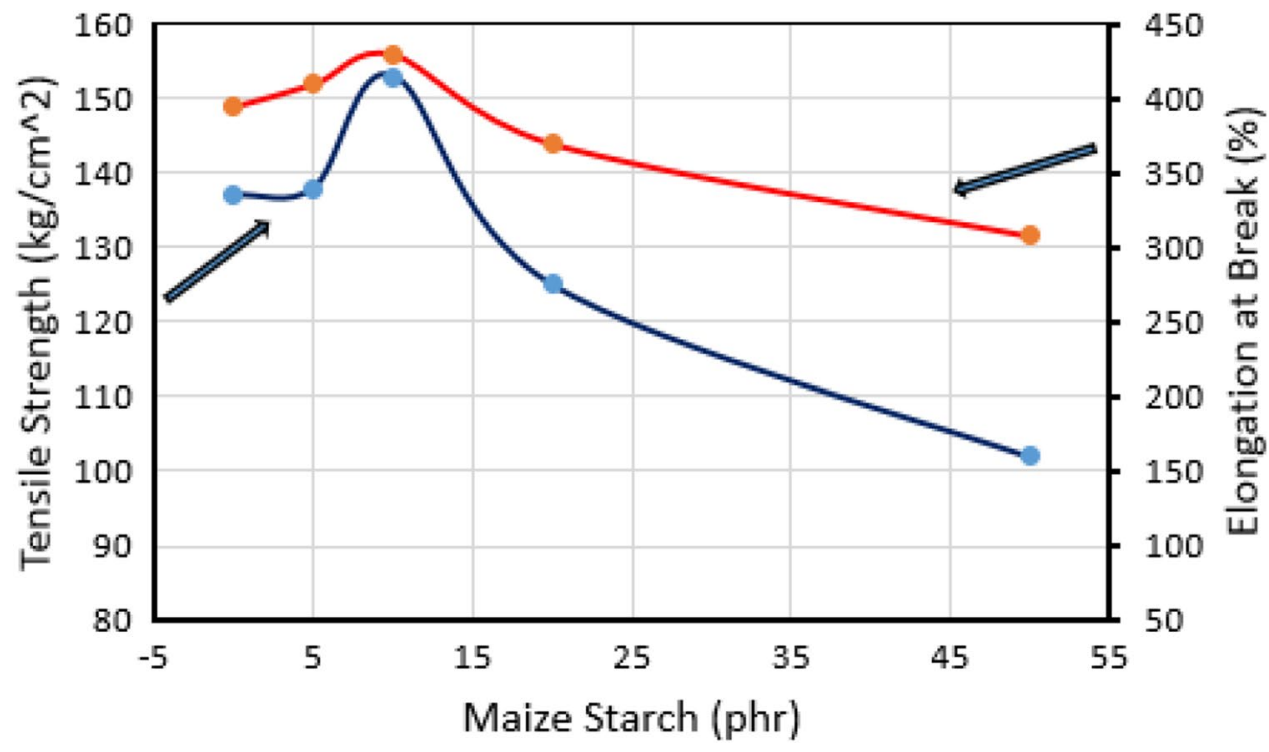

Fig. 3 MDR Rheo-graph for all rubber compounds

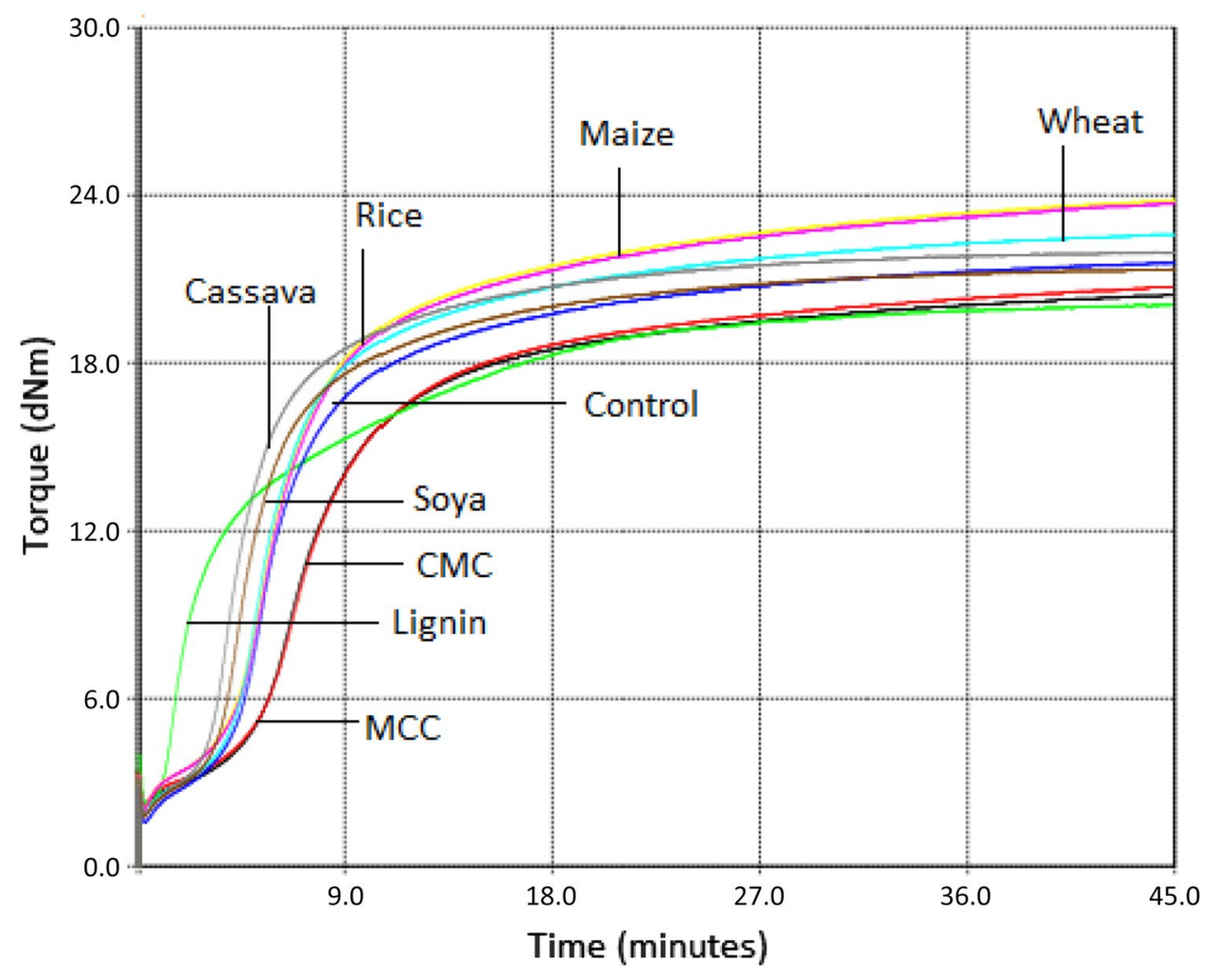

of heating increase in torque for all compounds is very similar, except compound containing lignin for which increase in torque is fastest and compounds containing soya and cassava also show faster increase in torque compared to that of control compound. Maize, rice and wheat starches show similar curing characteristics to control compound. This result indicates that cassava, lignin and soya accelerate sulphur curing/vulcanization of rubber compound. However, MCC and CMC decreases the rate of vulcanization. Since, biomaterials contains complex chemical structure, it is difficult to explain the reason for the acceleration and deacceleration effect.

TC50 and TC90, obtained from rheometric study, indicate time in minutes required for $50 \%$ and $90 \%$ curing, respectively. T50 and T90 for all compounds containing different types of biomaterials are shown in Fig. 4. Decrease in T50 and T90 after addition of biomaterials indicate acceleration of curing process and vice versa. From the 
Fig. 4 T50 and T90 for all rubber compounds obtained from MDR analysis

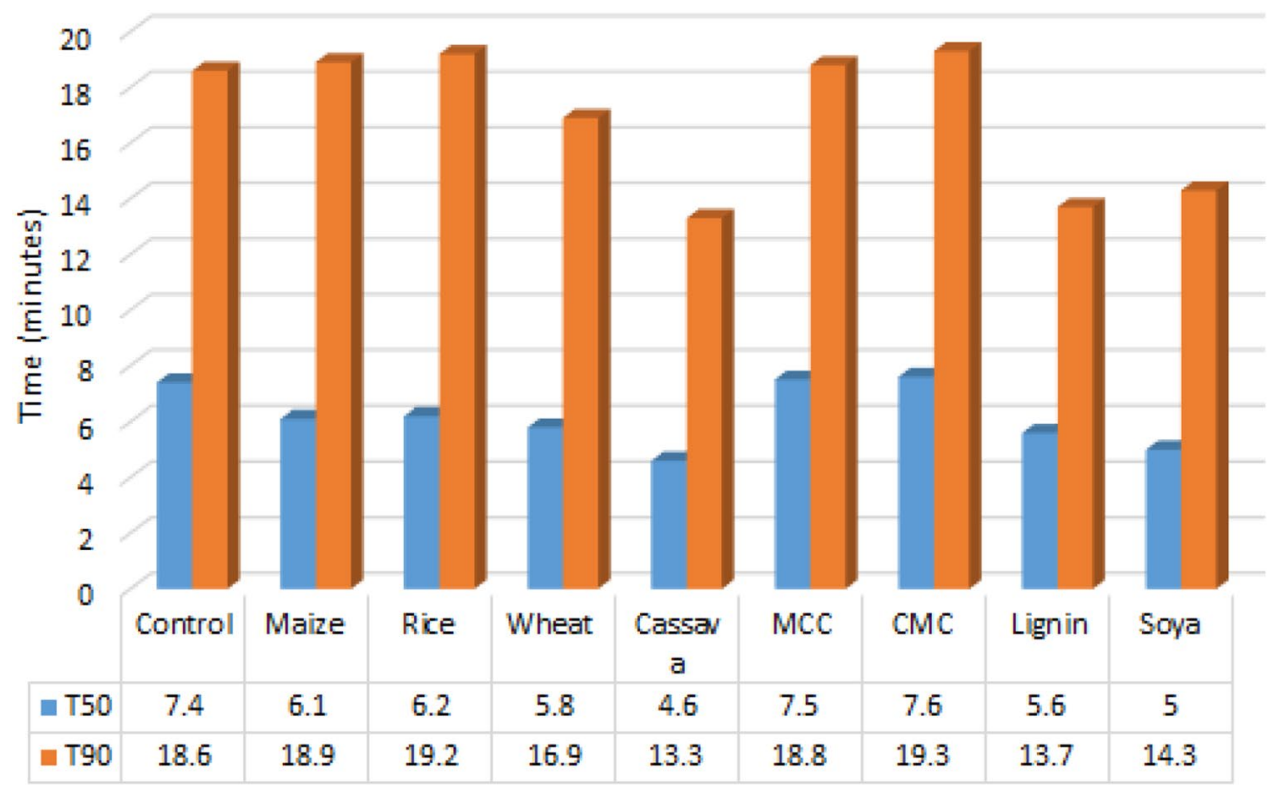

T50 and T90 values also it is clear that among all the biomaterials studied, cassava, lignin and soya accelerate the rate of curing, i.e. act as natural accelerator, while CMC and MCC retard the rate of curing, i.e. acts as natural retarder for sulphur vulcanization of rubber compound.

\subsection{Stress-strain properties}

Detailed stress-strain properties (before and after aging) for all vulcanized rubber compounds are shown in Table 3. Tensile modulus at different strain for all biomaterial containing samples were higher compared to control. This may be due to the presence of additional filler in biomaterial filled compounds, as biomaterials were added as a top up, not as a replacement of any existing filler present in control compound.

Figure 5 shows the tensile strength of all vulcanized rubber compounds before and after ageing. Tensile strength of all the samples before ageing are comparable except sample containing wheat starch, which shows $7.6 \%$ higher tensile strength and soya protein, which shows $11 \%$ higher tensile strength than that of control sample.

Table 3 Effect of different type of biomaterials (10 phr top up) on the mechanical properties of silica-based passenger car tire (PCR) tread compound

\begin{tabular}{|c|c|c|c|c|c|c|c|c|c|}
\hline Properties & Control & Maize & Rice & Wheat & Cassava & MCC & CMC & Lignin & Soya \\
\hline \multicolumn{10}{|l|}{ Before ageing } \\
\hline $50 \%$ Modulus $\left(\mathrm{kg} / \mathrm{cm}^{2}\right)$ & 14.5 & 16.9 & 16.8 & 16.3 & 15.4 & 16.1 & 15.7 & 15.1 & 16.6 \\
\hline $100 \%$ Modulus $\left(\mathrm{kg} / \mathrm{cm}^{2}\right)$ & 23.3 & 28.2 & 27.6 & 27.2 & 25.3 & 26.8 & 25.7 & 26.0 & 27.3 \\
\hline $200 \%$ Modulus $\left(\mathrm{kg} / \mathrm{cm}^{2}\right)$ & 48.3 & 58.7 & 53.3 & 56.6 & 55.0 & 50.4 & 48.5 & 53.9 & 52.8 \\
\hline $300 \%$ Modulus $\left(\mathrm{kg} / \mathrm{cm}^{2}\right)$ & 83.1 & 91.6 & 87.2 & 92.1 & 89 & 83.0 & 79.5 & 90.8 & 85.0 \\
\hline Tensile strength $\left(\mathrm{kg} / \mathrm{cm}^{2}\right)$ & 144 & 144 & 139 & 155 & 144 & 129 & 133 & 136 & 160 \\
\hline Elongation at break (\%) & 452 & 433 & 434 & 454 & 437 & 421 & 446 & 411 & 498 \\
\hline \multicolumn{10}{|l|}{ After ageing at $80^{\circ} \mathrm{C}$ for 7 days } \\
\hline $50 \%$ Modulus $\left(\mathrm{kg} / \mathrm{cm}^{2}\right)$ & 19.4 & 22.7 & 22.7 & 21.8 & 20.1 & 21.8 & 22.3 & 21.9 & 22.0 \\
\hline $100 \%$ Modulus $\left(\mathrm{kg} / \mathrm{cm}^{2}\right)$ & 32.6 & 38.9 & 38.7 & 38.2 & 34.3 & 38.2 & 39.5 & 41.8 & 36.8 \\
\hline $200 \%$ Modulus $\left(\mathrm{kg} / \mathrm{cm}^{2}\right)$ & 70.7 & 80.0 & 74.3 & 78.9 & 72.4 & 73.6 & 75.6 & 84.1 & 70.3 \\
\hline $300 \%$ Modulus $\left(\mathrm{kg} / \mathrm{cm}^{2}\right)$ & 119.6 & 120.0 & 117.2 & 121.7 & 112.8 & 118.3 & 120.8 & 126.2 & 110.0 \\
\hline Tensile Strength $\left(\mathrm{kg} / \mathrm{cm}^{2}\right)$ & 130 & 134 & 136 & 134 & 137 & 123 & 128 & 121 & 149 \\
\hline Elongation at break (\%) & 358 & 337 & 346 & 334 & 361 & 334 & 320 & 323 & 397 \\
\hline$\%$ Change in $300 \%$ modulus after ageing & +44 & +31 & +34 & +32 & +27 & +43 & +52 & +39 & +29 \\
\hline$\%$ Change in tensile strength after ageing & -10 & -7 & -2 & -13 & -8 & -5 & -2 & -11 & -7 \\
\hline$\%$ Change in elongation at break after ageing & -21 & -22 & -20 & -26 & -17 & -21 & -28 & -21 & -20 \\
\hline
\end{tabular}


Fig. 5 Tensile strength of all vulcanized rubber compounds before and after ageing

\section{Tensile strength $\left(\mathrm{kg} / \mathrm{cm}^{2}\right)$}

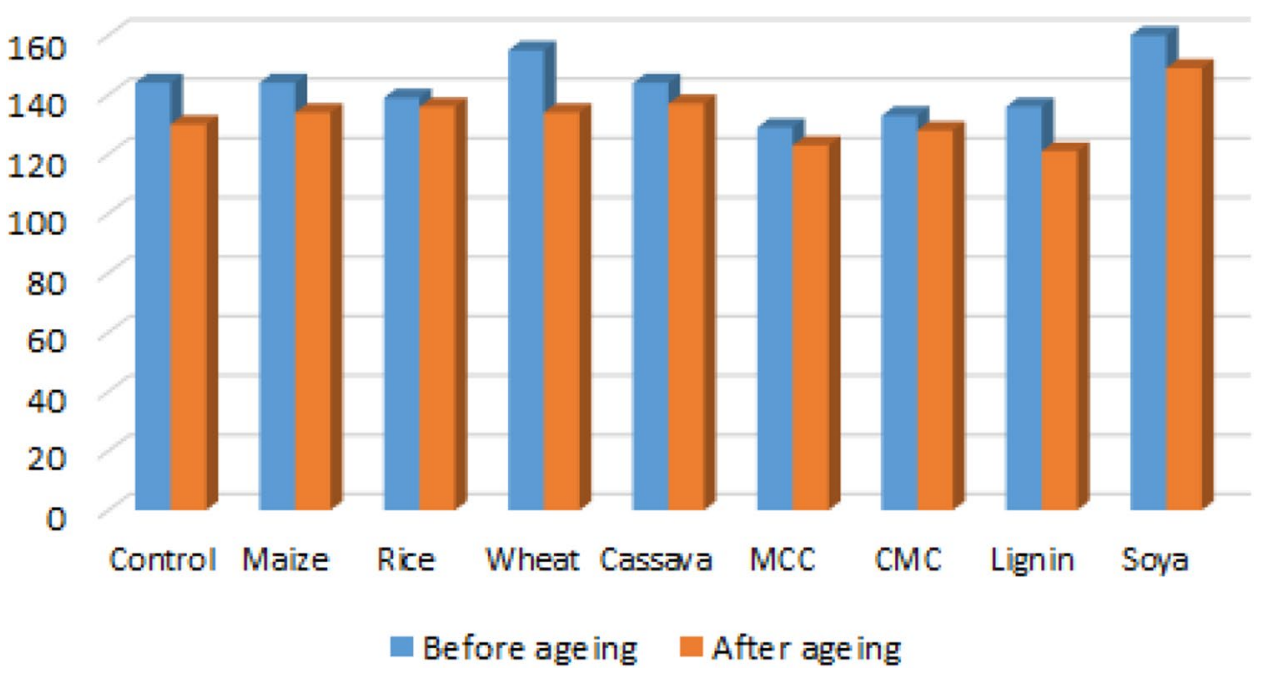

Whereas compounds containing MCC, CMC and lignin shows lower tensile strength than control compound.

Tensile strength after ageing is decreased for all rubber compounds. However, Percentage of deterioration of tensile strength after ageing is much lower in case of rice, MCC and CMC filled compounds compared to that of other compounds. The results indicate that rice, MCC and CMC has some antioxidant properties.

Figure 6 shows the elongation at break (EB) of all vulcanized rubber compounds before and after ageing. Before and after ageing, elongation at break of all the compounds are comparable, except soya filled compound, which shows approximately $10 \%$ higher elongation than control compound. There is marginal decrease in EB of unaged samples containing maize, rice, cassava, MCC and lignin, however it remains similar in case of wheat starch and CMC filled compounds.

\subsection{Hardness}

Hardness of all vulcanized rubber compounds before and after ageing is shown in Table 4 and Fig. 7. Hardness of all the compounds before ageing are comparable. However, after ageing increase in hardness is very high for MCC, CMC and lignin filled compound. Change in hardness of soya flour filled compound is comparable with control sample. This may be because some crosslink formation by MCC, CMC and lignin during ageing.
Fig. 6 Elongation at break of all vulcanized rubber compounds before and after ageing

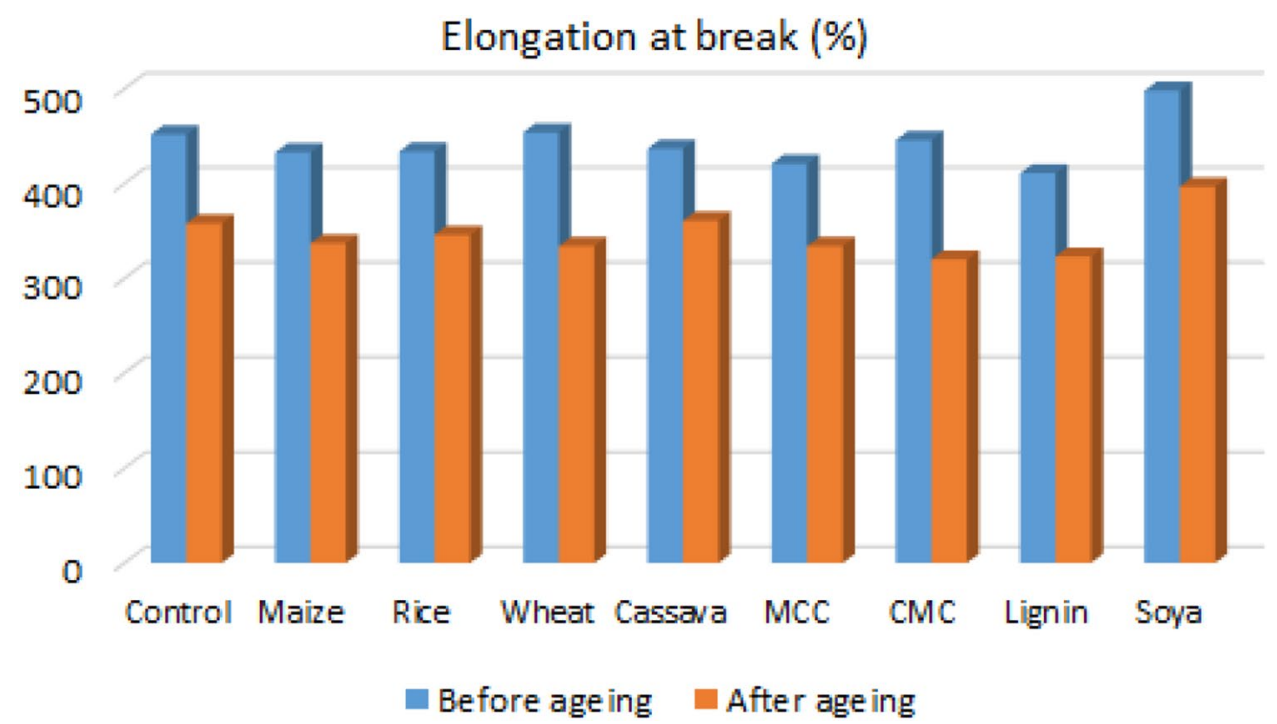


Table 4 Effect of different type of biomaterials on the hardness (before and after aging) of silica-based PCR tread compound

\begin{tabular}{|c|c|c|c|c|c|c|c|c|c|}
\hline Properties & Control & Maize & Rice & Wheat & Cassava & MCC & CMC & Lignin & Soya \\
\hline Hardness (shore A) (before ageing) & 71 & 73 & 72 & 70 & 69 & 70 & 72 & 71 & 70 \\
\hline $\begin{array}{l}\text { Hardness (shore A) (after ageing at } \\
80^{\circ} \mathrm{C} \text { for } 7 \text { days) }\end{array}$ & 74 & 75 & 74 & 75 & 74 & 77 & 78 & 77 & 73.0 \\
\hline$\%$ Change in hardness after ageing & +4.2 & +2.7 & +2.8 & +7.1 & +7.2 & +10.0 & +8.3 & +8.4 & +4.3 \\
\hline
\end{tabular}

Fig. 7 Hardness of all vulcanized rubber compounds before and after ageing

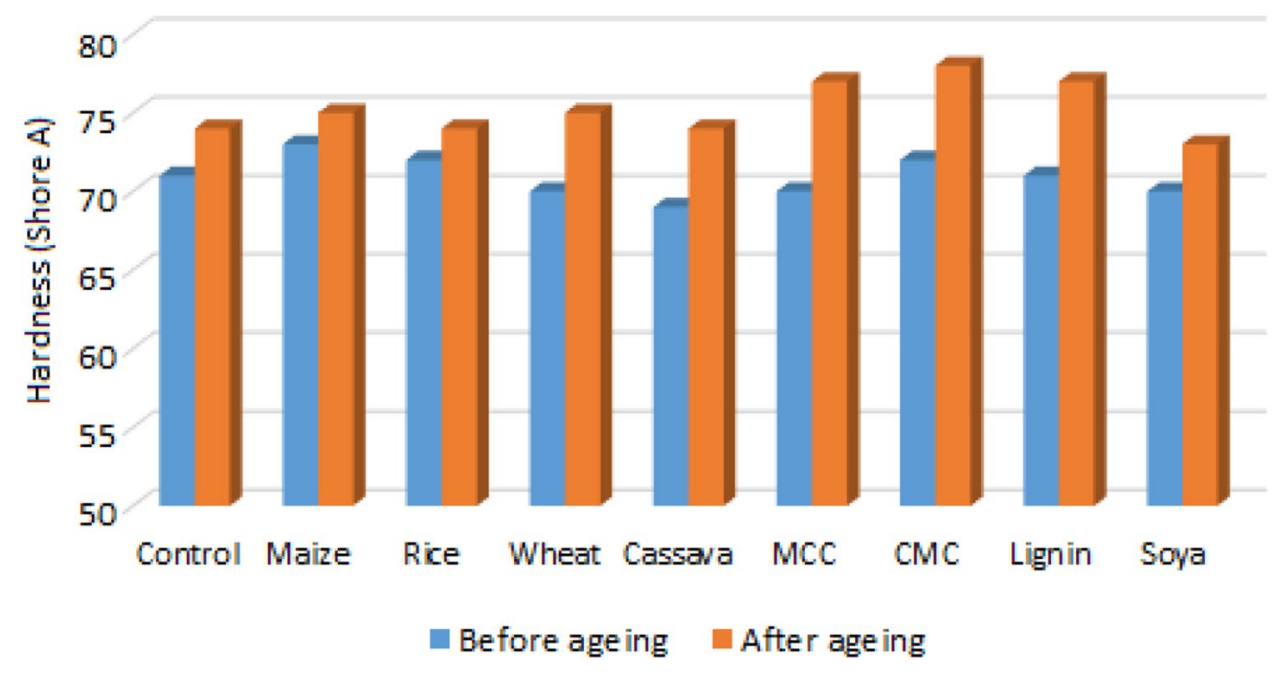

and recovery of weak physical bonds linking adjacent filler clusters. If strain is increased, the storage modulus of the compound is decreased. Higher the difference, higher is the breakage of network structure [47]. Payne effect is determined from the difference in shear modulus at $1 \%$ and $450 \%$ strain. Figure 9 . Shows the Log-Log plot of shear modulus versus strain obtained from RPA for all rubber compounds. The Payne effect is the minimum for controlled compound and marginally higher for all biomaterials filled compound. This may be due to inclusion of additional non-reinforcing biomaterials (topped up) in the formulation, which acted as a barrier between rubber and reinforcing fillers (silica \& carbon black). Among all biomaterials used, maize starch has minimum negative Payne effect and Soya protein has the maximum negative Payne effect.

\subsection{Abrasion property}

Abrasion properties of all the vulcanized rubber compounds are shown in Table 6 and Fig. 10. It is very clear from the volume loss or abrasion index that after addition of biomaterials abrasion is higher, i.e., wear property is deteriorated. However, drop in DIN index is significantly higher with lignin than other biomaterials. The increase in wear after the addition of biomaterials is since these behaviour of filled rubber compound. The Payne effect is used to understand the rubber-filler interaction, breakage 
Table 5 Effect of different type of biomaterials on the dynamic mechanical properties

\begin{tabular}{lccccccccc}
\hline Properties & Control & Maize & Rice & Wheat & Cassava & MCC & CMC & Lignin & Soya \\
\hline Storage modulus, E' (MPa) & 12.85 & 14.95 & 13.10 & 13.75 & 14.00 & 13.85 & 14.45 & 10.78 & 13.65 \\
Loss modulus, E" (MPa) & 1.70 & 2.07 & 1.79 & 1.86 & 1.93 & 2.01 & 2.15 & 1.47 & 1.92 \\
Tan delta & 0.132 & 0.138 & 0.136 & 0.135 & 0.138 & 0.138 & 0.144 & 0.136 & 0.141 \\
Change in tan $\delta$ w.r.t. & & +4.5 & +3.0 & +2.3 & +4.5 & +4.5 & +9.1 & +3.0 & +6.8 \\
$\quad$ control sample (\%) & & & & & & & & & \\
\hline
\end{tabular}

Fig. $8 \operatorname{Tan} \delta$ for all vulcanized from DMA

Fig. 9 Log-Log plot of shear modulus versus strain obtained from RPA for all rubber compounds

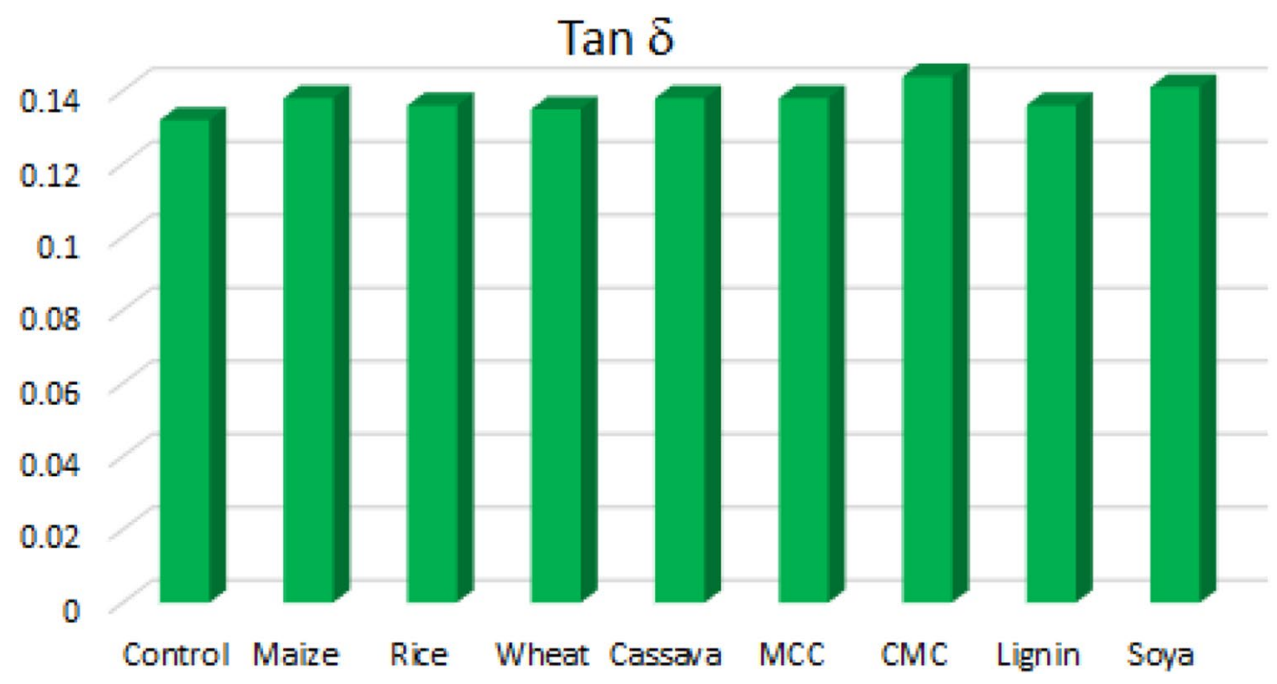
rubber compounds obtained

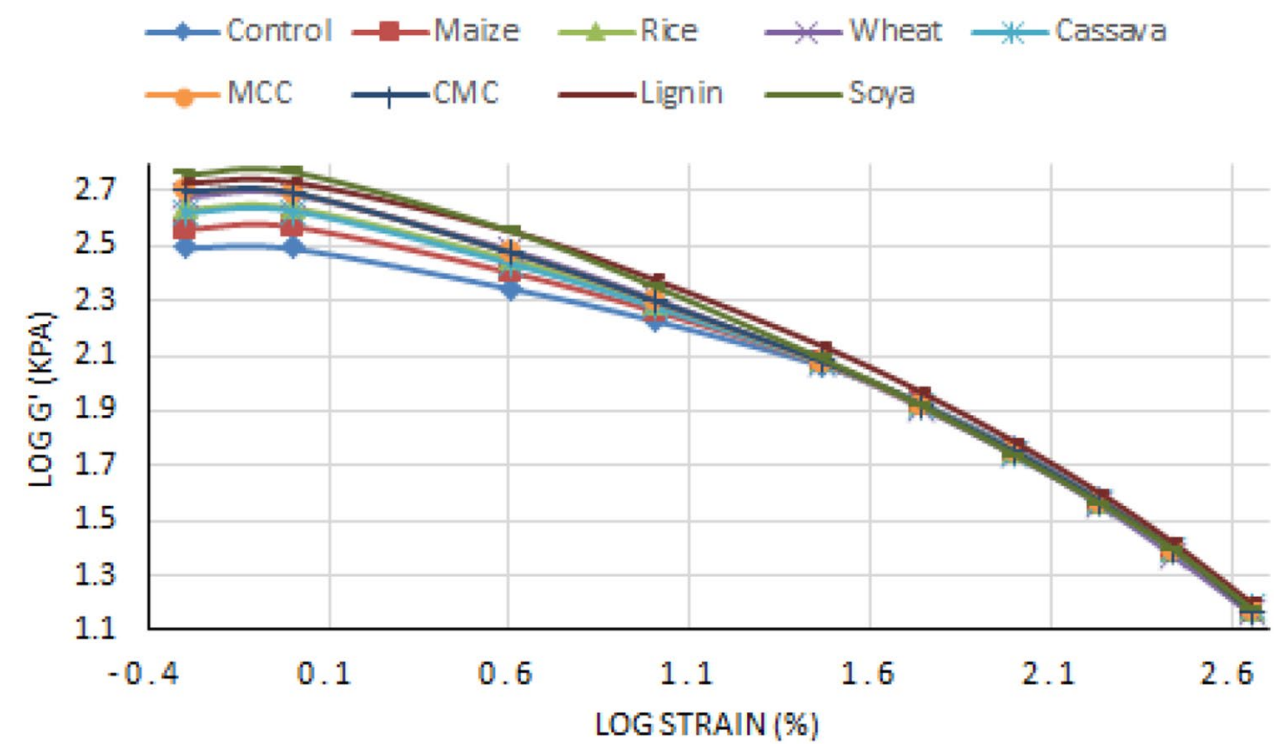

materials are non-reinforcing and act as barrier between the reinforcement of rubber-silica/carbon black. Therefore, these biomaterials may be used in tire tread compound only if the abrasion index is in acceptable limit or else may be used in non-tread compounds, which are not in contact with road.

\subsection{Thermogravimetric analysis (TGA)}

Thermal stability of the compounds was studied from TGA. Figure 11 shows the TGA thermogram of all the compounds. All compounds show similar trend of decomposition. For biomaterial filled compounds, there is higher percentage of weight loss between the temperature range 
Table 6 Effect of different type of biomaterials on the DIN abrasion of the final compound

\begin{tabular}{lcccccccccc}
\hline Properties & Control & Maize & Rice & Wheat & Cassava & MCC & CMC & \multicolumn{2}{c}{ Lignin } & Soya \\
\hline Std. loss avg (gm) & 0.194 & 0.194 & 0.189 & 0.189 & 0.188 & 0.188 & 0.185 & 0.185 & 0.188 \\
Sample loss (gm) & 0.143 & 0.170 & 0.171 & 0.166 & 0.166 & 0.163 & 0.164 & 0.146 & 0.173 \\
Vol. loss (mm ${ }^{3}$ ) & 126.75 & 158.17 & 162.07 & 157.36 & 158.67 & 155.25 & 159.26 & 142.16 & 165.48 \\
DIN abrasion index (\%) & 117.8 & 94.4 & 92.1 & 94.9 & 94.1 & 96.1 & 93.7 & 105.0 & 90.2 \\
\hline
\end{tabular}

Fig. 10 DIN abrasion index of all vulcanized rubber compounds
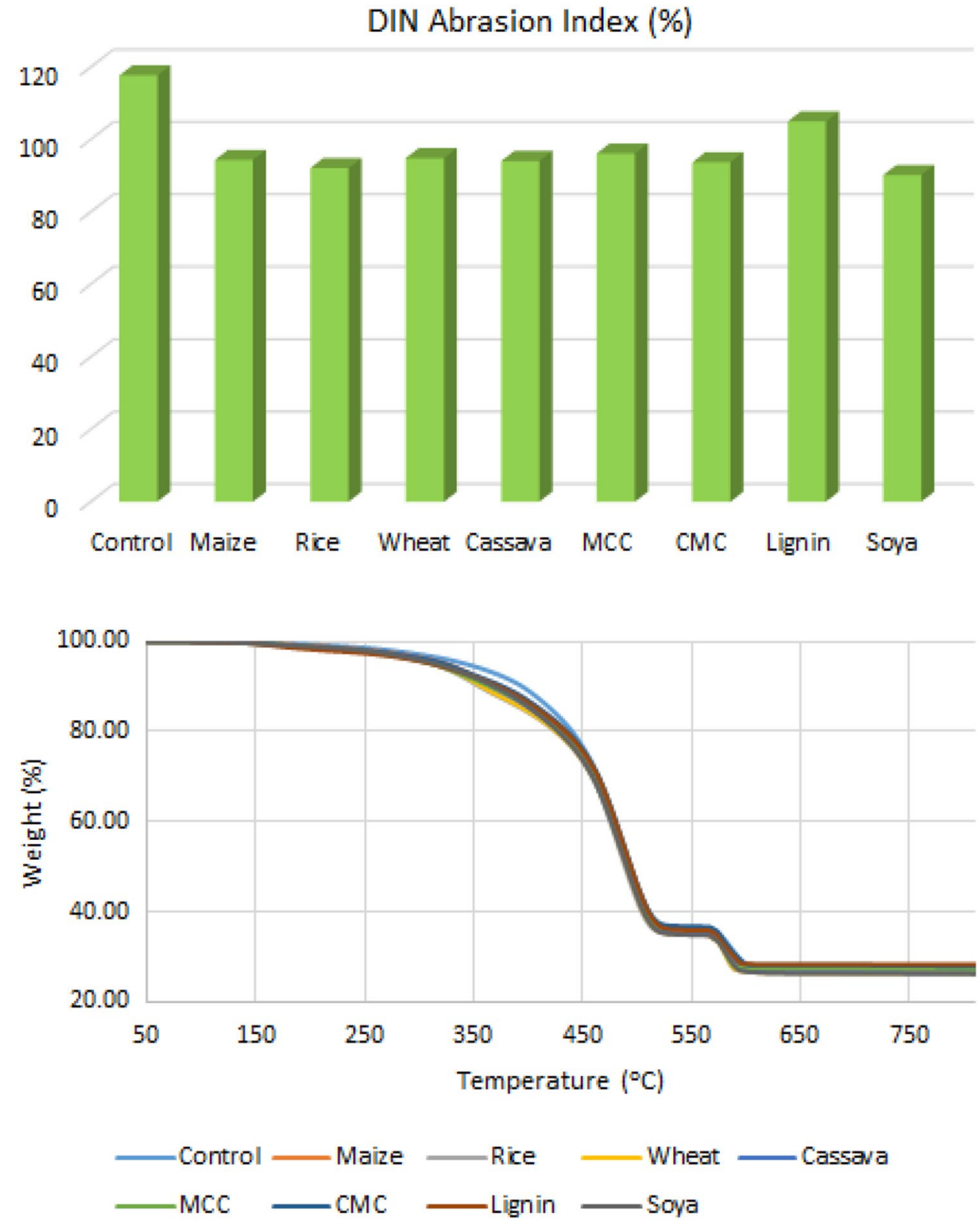

Fig. 11 TGA thermogram of all compounds

$300-450^{\circ} \mathrm{C}$ than that of control compound. This is due to the additional biomaterials (topped up) present in those compounds, which decomposes in that temperature range.

Most of the biomaterials used in this study act as non-reinforcing filler except wheat and soya flour, which show semi reinforcing effect causing improvement in mechanical properties. There is no additional deterioration of aged properties due to the presence of biomaterials and hence can be used in tire. Aged properties of soya filled compound is better compared to that of other compounds. For tire application lesser change in aged properties are expected. Soya also accelerates vulcanization reaction. Considering all aspects, soya flour is the 
best biomaterials among all the biomaterials studied for tire application. However, it is to be noted that addition of biomaterials causes an increase in marginal rolling resistance, increase in Payne effect and significant deterioration in wear property. If the final properties after the addition of biomaterials are with in the acceptable range, then only those can be used in tire tread compound, otherwise may be used in non-tread compounds.

\section{Conclusion}

Biomaterials are renewable, leave less carbon footprint, lower cost, lesser weight. We have incorporated (10 phr, top up) different type of starches, such as maize, wheat, rice, cassava, and cellulosic materials, such as microcrystalline cellulose (MCC), sodium carboxymethyl cellulose (CMC), natural proteins, such as soya bean flour, and lignin in a silica filled tire tread compound to identify suitable biomaterials for the application in tire. Among all these biomaterials, wheat, cassava, lignin and soya accelerate rate of vulcanization. Therefore, these materials can be used as bio-accelerator. Wheat starch imparts $7.6 \%$ improvement in tensile strength. Soya proteins imparts approximately $11 \%$ improvement in tensile strength and approximately $10 \%$ improvement in elongation at break. Storage modulus at low strain $\left(E^{\prime}\right)$ of all the compounds containing biomaterials, except lignin, increases than that of control compound. Tan $\delta$ value for all the biomaterials filled compounds are little higher than control sample, but the resultant rolling loss of tire is expected to be negligible. The Payne effect is marginally higher for all biomaterials filled compound than that of controlled compound. Wear property after the addition of biomaterials deteriorated significantly. Among all the biomaterials studied, soya protein accelerate rate of vulcanization, improves mechanical properties, shows minimum deterioration in properties after ageing. Therefore, soya protein is the most suitable biomaterials among the materials studied for application in tire compound.

\section{Compliance with ethical standards}

Conflict of interest The authors declare that they have no conflict of interest.

\section{References}

1. Nakason C, Kaesaman A, Eardrod K (2005) Cure and mechanical properties of natural rubber-g-poly(methyl methacrylate)-cassava starch compounds. Mater Lett 59:4020
2. Nakason C, Kaesman A, Homsin S, Kiatkamjornwong S (2001) Rheological and curing behavior of reactive blending I Maleated natural rubber-cassava starch. J Appl Polym Sci 81:2803

3. Liu C, Shao Y, Jia D (2008) Chemically modified starch reinforced natural rubber composites. Polymer 49:2176

4. Wu Y, Ji M, Qi Q, Wang Y, Zhang L (2004) Preparation, structure, and properties of starch/rubber composites prepared by cocoagulating rubber latex and starch paste. Macromol Rapid Commun 25:565

5. Wu Y, Qi Q, Liang G, Zhang L (2006) A strategy to prepare high performance starch/rubber composites: in situ modification during latex compounding process. Carbohyd Polym 65:109

6. Tang H, Qi Q, Wu Y, Liang G, Zhang L, Ma J (2006) Reinforcement of elastomer by starch. Macromol Rapid Commun 291:629

7. Li M, Ge X, Cho U (2013) Emulsion grafting vinyl monomers onto starch for reinforcement of styrene-butadiene rubber. Macromol Res 21:519

8. Li M, Cho U (2013) Emulsion grafting vinyl monomers onto starch for reinforcement of styrene-butadiene rubber. Mater Lett 92:132

9. Angellier H, Molina-Boisseau S, Lebrun L, Dufresne A (2005) Processing and structural properties of waxy maize starch nanocrystals reinforced natural rubber. Macromolecules 38:3783

10. Angellier H, Molina-Boisseau S, Dufresne A (2005) Mechanical properties of waxy maize starch nanocrystal reinforced natural rubber. Macromolecules 38:9161

11. Corvasce FG, Linster TD, Thielen G (1997) Starch composite reinforced rubber composition and tire with at least one component thereof. US5672639A

12. Corvasce FG, Fourgon FAJ (2005) Preparation of starch reinforced rubber and use thereof in tires. US6878760B2

13. Materne TFE, Corvasce FG (2001) Tire with tread of rubber composition prepared with reinforcing fillers which include starch/ plasticizer composite. US6273163B1

14. Sandstrom PH (2001) Rubber containing starch reinforcement and tire having component thereof. US6391945B2

15. Sandstrom PH (1999) Rubber containing starch reinforcement and tire having component thereof. US6269858B1

16. Haghighat $M$, Zadhoush A, Khorasani SN (2005) Physicomechanical properties of a-cellulose-filled styrene-butadiene rubber composites. J Appl Polym Sci 96:2203

17. Zhang W, Zhang X, Liang M, Lu C (2008) Mechanochemical preparation of surface-acetylated cellulose powder to enhance mechanical properties of cellulose-filler-reinforced NR vulcanizates. Compos Sci Technol 68:2479

18. Cao X, Xu C, Liu Y, Chen Y (2013) Preparation and properties of carboxylated styrene-butadiene rubber/cellulose nanocrystals composites. Carbohydr Polym 92:69

19. Abraham E, Deepa B, Pothan LA, John M, Narine SS, Thomas $S$, Anandjiwala R (2013) Physicomechanical properties of nanocomposites based on cellulose nanofibre and natural rubber latex. Cellulose 20:417

20. Lopattananon N, Jitkalong D, Seadan M (2011) Hybridized reinforcement of natural rubber with silane-modified short cellulose fibers and silica. J Appl Polym Sci 120:3242

21. Chen WJ, Gu J, Xu SH (2014) Exploring nanocrystalline cellulose as a green alternative of carbon black in natural rubber/butadiene rubber/styrene-butadiene rubber blends. Express Polym Lett 8:659

22. Bahl K, Miyoshi T, Jana SC (2014) Hybrid fillers of lignin and carbon black for lowering of viscoelastic loss in rubber compounds. Polymer 55:3825

23. Lora JH, Trojan MJ, Klingensmith WH (1990) Rubber compositions containing high purity lignin derivatives. US5196460A 
24. Jiang $\mathrm{C}$, He $\mathrm{H}$, Jiang $\mathrm{H}$, Ma L, Jia DM (2013) Nano-lignin filled natural rubber composites: preparation and characterization. Express Polym Lett 7:480

25. Košíková B, Gregorová A, Osvald A, Krajčovičová J (2007) Role of lignin filler in stabilization of natural rubber-based composites. J Appl Polym Sci 103:1226

26. Košíková JB, Gregorová A (2005) Sulfur-free lignin as reinforcing component of styrene-butadiene rubber. J Appl Polym Sci 97:924

27. Kumaran MG, De SK (1978) Utilization of lignins in rubber compounding. J Appl Polym Sci 22:1885

28. Barana D, Ali SD, Salanti A, Orlandi M, Castellani L, Hanel T, Zoia $L$ (2016) Influence of lignin features on thermal stability and mechanical properties of natural rubber compounds. ACS Sustain Chem Eng 4:5258

29. Davidson MJG, Wunder RH (1975) Latex coagulation process using lignin compound. US4025711 A

30. Yu P, He H, Jia Y, Tian S, Chen J, Jia D, Luo Y (2016) A comprehensive study on lignin as a green alternative of silica in natural rubber composites. Polym Test 54:176

31. Jong $L$ (2005) Characterization of defatted soy flour and elastomer composites. J Appl Polym Sci 98:353

32. Jong $L$ (2005) Rubber composites reinforced by soy spent flakes. Polym Int 54:1572

33. Jong $L$ (2006) Effect of soy protein concentrate in elastomer composites. Compos Part A Appl Sci Manuf 37:438

34. Jong $L$ (2007) Effect of soy spent flakes and carbon black co-filler in rubber composites. Compos Part A Appl Sci Manuf 38:252

35. Mohanty AK, Wu Q, Selke S (2005) "Green" materials from soy meal and natural rubber blends. US7649036B2

36. Wu Q, Selke S, Mohanty AK (2007) Processing and properties of biobased blends from soy meal and natural rubber. Macromol Mater Eng 292:1149
37. Corvasce FG, Linster TD, Thielen G (1997) Starch composite reinforced rubber composition and tire with at least one component thereof. EP0795581A1

38. Sandstrom PH (2000) Rubber containing starch reinforcement and tire having component thereof. EP1074582A1

39. Vasseur D, Nourry C, Kobayashi K (2011) Rubber composition that can be used for manufacturing a tyre of which the composition comprises a starch and an aqueous or water-soluble plasticizer. US20130231417A1

40. Klinkenberg MPCJ, Thielen GMV (2007) Tire with component containing cellulose. US20090082511A1

41. Basu SK, Helmer BJ, Shelby MD, Wood MD, Dagenhart CS, De Wit JSD, Testa CA (2012) Tires comprising cellulose ester/elastomer compositions. US9273195B2

42. Basu SK, Helmer BJ (2012) Cellulose esters in pneumatic tires. WO2013086086A1

43. Veas C, Hotaling EL (2008) Lignin in tire components. WO2009145784A1

44. Hanel T, Castellani L, Orlandi M, Frigerio P, Zoia L (2012) Tyre for vehicle wheels. WO2014097108A1

45. Tochika S (2011) Rubber composition for pneumatic tire. US20120232192A1

46. Sarkaw SS, Kaewsakul W, Sahakaro K, Dierkes WK, Noordermeer JWM (2015) A review on reinforcement of natural rubber by silica fillers for use in low-rolling resistance tyres. J Rubber Res 18(4):203

47. Payne AR (1962) The dynamic properties of carbon black-loaded natural rubber vulcanizates. Part I. J Appl Polym Sci 6(19):53

Publisher's Note Springer Nature remains neutral with regard to jurisdictional claims in published maps and institutional affiliations. 